\title{
Effect of TNF-a concentration on selected clinical parameters of swine after burns
}

\author{
Roman Aleksiewicz ${ }^{1}$, Krzysztof Lutnicki ${ }^{2}$, Marta Likus ${ }^{3}$, Łukasz Gątkiewicz ${ }^{4}$ \\ ${ }^{1}$ Unit of Animal Surgery and Diagnostic Imaging, Faculty of Veterinary Medicine and Animal Science, \\ Poznań University of Life Sciences, 60-637 Poznań, Poland \\ ${ }^{2}$ Department and Clinic of Animal Internal Diseases, Faculty of Veterinary Medicine, \\ University of Life Sciences, 20-612 Lublin, Poland \\ ${ }^{3}$ Society of Silesian Veterinary Polyclinic, 40-453 Katowice, Poland \\ ${ }^{4}$ EVAN Veterinary Surgery, 41-253 Czeladź, Poland \\ provet1@poczta.onet.pl
}

Received: April 29, $2018 \quad$ Accepted: September 21, 2018

\begin{abstract}
Introduction: The study aimed to observe TNF- $\alpha$ serum concentration as well as changes in respiration rate, body temperature, and pulse rate in burn victims during $84 \mathrm{~h}$ post burn. Material and Methods: A total of 30 healthy pigs were divided into two groups: A, the test group and N, the control group. The experimental group suffered burns to $30 \%$ of the body surface, and after infliction of the burns both groups were closely monitored. Results: The biggest increase in TNF- $\alpha$ serum concentration in the test subjects occurred around the $6^{\text {th }} \mathrm{h}$ of the study, and the second biggest increase took place between $12^{\text {th }}$ and $36^{\text {th }} \mathrm{h}$. In the $36^{\text {th }} \mathrm{h}$, TNF- $\alpha$ was 2.5 times more concentrated in serum in the test group than in the control group. In the test group, the biggest increase in respiration rate occurred up to the $6^{\text {th }} \mathrm{h}$ post burn, on average up to $29 / \mathrm{min}$. In the $12^{\text {th }} \mathrm{h}$ post burn, the mean pulse rate in the test group was $133 / \mathrm{min}$ and dropped to the lowest value in the $72^{\text {nd }} \mathrm{h}$ of the experiment. A gradual increase in body temperature up to $41.72^{\circ} \mathrm{C}$ was observed up to the $30^{\text {th }} \mathrm{h}$ post burn and decreased to a significant value of $40.74^{\circ} \mathrm{C}$ by the $84^{\text {th }} \mathrm{h}$ of the study. Conclusion: In a period of a pronounced rise in TNF- $\alpha$ serum concentration, this parameter, pulse rate, and respiration rate are highly correlated and are also influenced by multiple inflammation forming factors.
\end{abstract}

Keywords: burn injury, TNF- $\alpha$, swine, systemic inflammatory response syndrome.

\section{Introduction}

Thermal energy, ionising radiation, electrical current or chemical substances can cause burns, the consequences of which depend on their degree and severity. Mild and severe burns cause systemic disturbances called burn disease (1, 2, 16), a phenomenon of which is an increase in proinflammatory cytokine (IL-1 $\beta$, TNF- $\alpha$, IL-6) concentration, stimulating local and systemic inflammatory response. Its beneficial influence ends when a catabolic reaction in tissues and organs occurs. Generation and persistence of increased concentration of TNF- $\alpha$ and IL- 1 in the body subsequent to the burn cause loss of appetite, negative energy balance, loss of body mass, and immune system impairment. In the first $48 \mathrm{~h}$ subsequent to the burn, changes in hypothalamus thermoregulating system lead to the development of hypermetabolic syndrome $(1,5,16)$ and systemic inflammatory response syndrome (SIRS) $(3,4,27)$. The consequence of an increase in inflammation mediator concentration is the development of septicaemia and multiorgan destruction syndrome (MODS) $(15,26)$. The secretion of large amounts of TNF- $\alpha$ increases catabolic hormone secretion and internal temperature. There is no data in the literature on simultaneous and associated changes in TNF- $\alpha$ concentration and basic clinical parameters (body temperature, pulse, and respiration rate) in swine after II and III degree burns. In burn studies, in vivo models are still irreplaceable and necessary to elucidate the mechanisms of burn healing on a cellular and molecular level and to develop new treatment strategies $(12,27)$. Among many possible animal models, the domestic swine is 
the most appropriate one for conducting burn disease studies. This is due to its similarities to the human, which are anatomical, physiological, and also in burn hypermetabolic reaction (27).

The aim of this study was to assess the correlation between serum concentration of TNF- $\alpha$ and changes in basic vital parameters (heart rate, respiration rate, and body temperature) in swine in the course of SIRS after a thermal burn injury. There are no reports on this interdependency, concerning severe skin burns in swine in the available literature.

\section{Material and Methods}

A total of 30 healthy Polish Landrance mixed sex pigs (21 females and nine castrated males), weighing $50 \mathrm{~kg}( \pm 2 \mathrm{~kg})$, were used. The animals were divided into two equal groups: group A which was burnt and group $\mathrm{N}$ which was the control and not burnt. The acclimatisation period prior to the experiment was seven days, in a day/night lighting system. The animals were fed a complete swine feed and received water ad libitum, but $24 \mathrm{~h}$ prior to the commencement of the experiment the animals received only drinking water. The timeline of the experiment was set for $84 \mathrm{~h}$ from the time of the burn $(8,20)$.

Prior to injury by the burn, the animals from both groups were weighed and premedicated (atropinum sulfuricum $0.04 \mathrm{mg} / \mathrm{kg}$ b.w., sc. and butorphanol $0.02 \mathrm{mg} / \mathrm{kg}$ b.w., sc.). After $30 \mathrm{~min}$, azaperon (3 mg/kg b.w.) and ketamine (10 $\mathrm{mg} / \mathrm{kg}$ b.w. im.) were administered. Infusion anaesthesia was performed with pentobarbital (6 mg/kg b.w. iv.). The Seldinger method was used for the approach to the external jugular vein.
The burn was inflicted by applying a $2.5 \mathrm{~kg}$ burner of $200^{\circ} \mathrm{C}$ for $10 \mathrm{~s}$. The number of necessary placements of the burner was determined, using the formula: BSA $\left(\mathrm{cm}^{2}\right)=734 \mathrm{BW}^{0.656} \mathrm{~kg}$ to obtain II and III degree burns of $30 \pm 2 \%$ of body surface. A computer-controlled Touch/Burn (T/B) heating plate of our own construction (Polish Patent No. 213590) was used for injuring the study animals thermally (24). The verification of the burn degree was obtained through histological examination. Blood was collected from the external jugular vein before the burn and at the $6^{\text {th }}, 12^{\text {th }}$, $18^{\text {th }}, 24^{\text {th }}, 30^{\text {th }}, 36^{\text {th }}, 42^{\text {nd }}, 48^{\text {th }}, 60^{\text {th }}, 66^{\text {th }}, 72^{\text {nd }}, 78^{\text {th }}$, and $84^{\text {th }} \mathrm{h}$ post burn. Prior to each blood collection, respiration rate, pulse rate, and body temperature were recorded. TNF- $\alpha$ concentration in serum was measured with a Quantikine Porcine TNF-/TNFSF1A ELISA kit (cat. no. PTA00, R\&D Systems, USA), according to the manufacturer's instructions.

The results obtained were subjected to mathematical statistical analysis with Statistica 12.0 software by StatSoft (USA). Statistical significance was determined at $\mathrm{P}<0.05$. To determine the statistical significance of variables, the test for independent samples was used, assuming a significance value of $\mathrm{P}<0.05$. Interdependencies between variables were evaluated using correlation coefficients (r) according to Pearson. The Stanisz scale was used to interpret the correlation between the parameters.

\section{Results}

The clinical parameters and TNF- $\alpha$ concentration in experimental animals (A) and in control animals (N) are shown in Figs 1, 2, and 3.

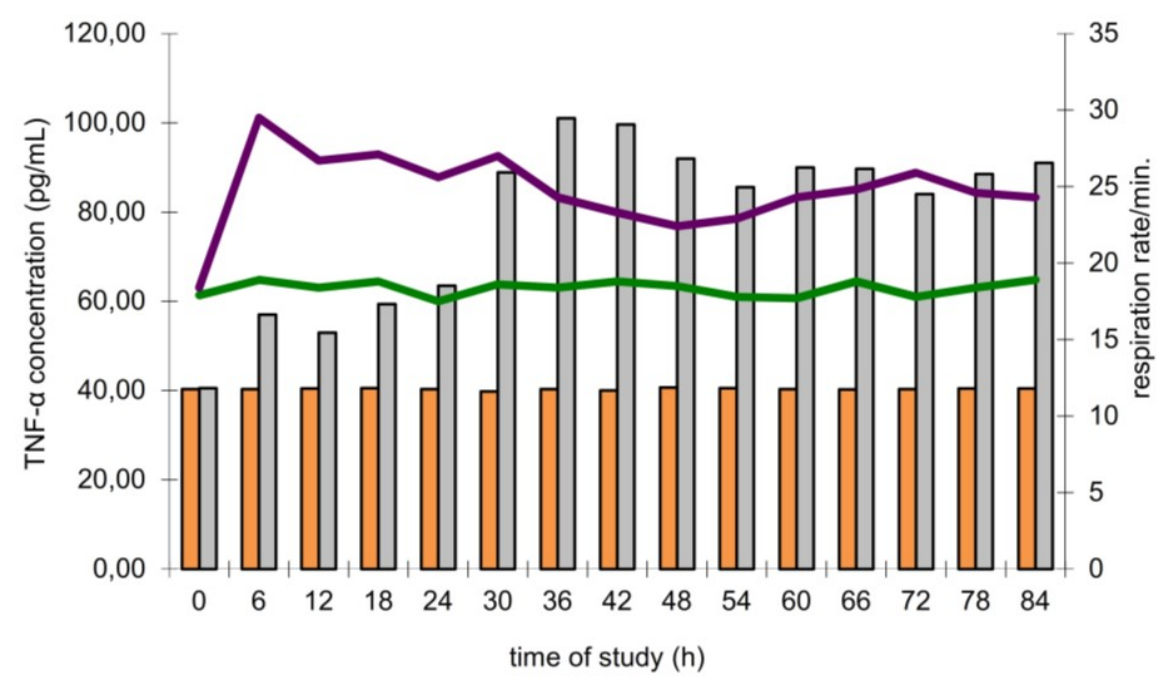

$\square$ group N TNF- $\alpha \square$ group A TNF- $\alpha \rightleftharpoons$ group N respiration rate group A respiration rate

Fig. 1. Changes in respiration rate and TNF- $\alpha$ concentration in groups $\mathrm{N}$ and $\mathrm{A}$ 


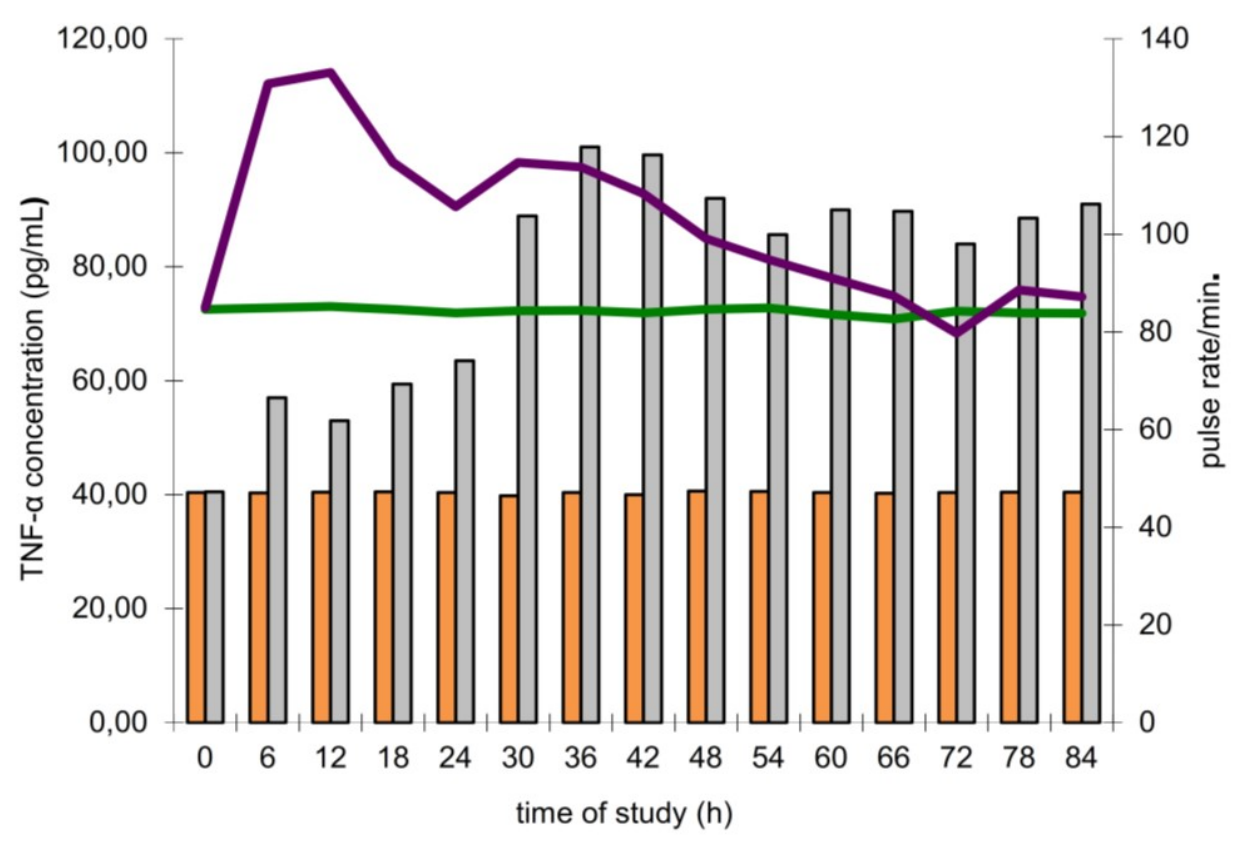

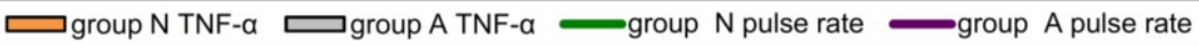

Fig. 2. Changes of pulse rate and TNF- $\alpha$ concentration in groups $\mathrm{N}$ and $\mathrm{A}$

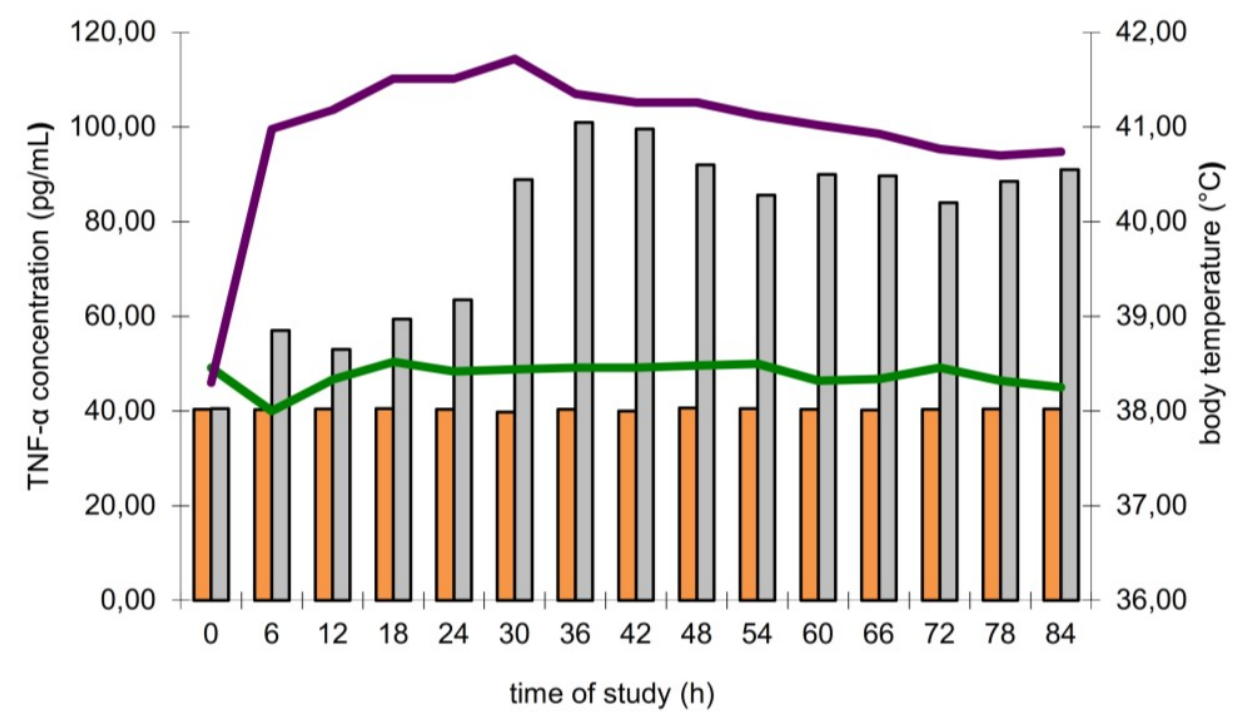

שgroup N TNF-a $\square$ group A TNF- $\alpha \quad$ group N body temp.

group A body temp.

Fig. 3. Changes of body temperature and TNF- $\alpha$ concentration in groups $\mathrm{N}$ and A

The change of respiration rate in the control group was not statistically significant, and the mean value was $18 / \mathrm{min}$. In the test group, the biggest increase in respiration rate occurred up to the $6^{\text {th }} \mathrm{h}$ post burn, on average up to $29 / \mathrm{min}$, and then between the $6^{\text {th }}$ and $48^{\text {th }} \mathrm{h}$ a gradual decrease in respiration rate was observed $(\mathrm{P}<0.05)$. Between the $48^{\text {th }}$ and $72^{\text {nd }} \mathrm{h}$ of testing, a gradual increase in average respiration rate to $26 / \mathrm{min}$ occurred again $(\mathrm{P}<0.05)$, followed by another drop. In the $84^{\text {th }} \mathrm{h}$ of the test, the respiration rate was $5 / \mathrm{min}$ higher than in the control group $(\mathrm{P}<0.05)$.

The average pulse rate in the control group during the whole experiment was $84 / \mathrm{min}$. In the $12^{\text {th }} \mathrm{h}$ post burn, the mean pulse rate in the test group was $133 / \mathrm{min}$ 
$(\mathrm{P}<0.05)$, then between the $12^{\text {th }}$ and $42^{\text {nd }} \mathrm{h}$ it gradually dropped to $108 / \mathrm{min}(\mathrm{P}<0.05)$. Between the $42^{\text {nd }}$ and $48^{\text {th }} \mathrm{h}$ of the test, the average pulse rate in group A was $98 / \mathrm{min}$, and between the $48^{\text {th }}$ and $72^{\text {nd }} \mathrm{h}$ another drop in pulse rate occurred, with the rate the furthest below that of the control group $(\mathrm{P}<0.05)$ coming the $72^{\text {nd }} \mathrm{h}$. Between the $72^{\text {nd }}$ and $84^{\text {th }} \mathrm{h}$, the average pulse rate increased to $88 / \mathrm{min}$ at the end of study $(\mathrm{P}<0.05)$.

The average value of body temperature in the control group $\mathrm{N}$ during the whole study was $38.3^{\circ} \mathrm{C}$. The average body temperature in group A increased significantly up to the $30^{\text {th }} \mathrm{h}$ post burn, reaching $41.72^{\circ} \mathrm{C}(\mathrm{P}<0.05)$. Then, it started decreasing to reach the statistically significant value of $40.74^{\circ} \mathrm{C}$ in the $84^{\text {th }} \mathrm{h}$, comparable to the value in the $6^{\text {th }} \mathrm{h}$ of the experiment $(\mathrm{P}<0.05)$.

The average concentration of TNF- $\alpha$ in the control group did not change significantly throughout the experiment and amounted to $40.35 \mathrm{pg} / \mathrm{mL}$. In the experimental group, the first significant increase in the
TNF- $\alpha$ concentration occurred in the $6^{\text {th }} \mathrm{h}$ post burn $(\mathrm{P}<0.05)$. Between the $6^{\text {th }}$ and $12^{\text {th }} \mathrm{h}$ of the study, the concentration slightly decreased by $4 \mathrm{pg} / \mathrm{mL}$, followed by another increase between the $12^{\text {th }}$ and $36^{\text {th }} \mathrm{h}$, and in the $36^{\text {th }} \mathrm{h}$ was 2.5 times higher than in the control group ( $\mathrm{P}<0.05)$. From then until the end of the study, minor increases and decreases in concentration were observed. Between the $36^{\text {th }}$ and $54^{\text {th }} \mathrm{h}$, the most significant decrease compared to group $\mathrm{N}$ was noted $(\mathrm{P}<0.05)$, whereas between the $54^{\text {th }}$ and $84^{\text {th }} \mathrm{h}$ a slight increase was observed. At the end of the study, the concentration of TNF- $\alpha$ was two times higher than that of group $\mathrm{N}(\mathrm{P}<0.05)$.

The analysis of the correlation between the TNF- $\alpha$ concentration in serum and body temperature, pulse rate, and respiration rate was carried out in two periods from the 0 to $36^{\text {th }} \mathrm{h}$ and from the $36^{\text {th }}$ to $84^{\text {th }} \mathrm{h}$ post burn. The values of correlation coefficients (r) for the studied dependencies and the changes in their values in individual periods of the study are shown in Table 1 .

Table 1. Established dependencies and values of correlation coefficient (r) in study periods (group A)

\begin{tabular}{llcc}
\hline & \multicolumn{3}{c}{ Study period } \\
\hline Correlation & $0-36$ & $36-84$ & $0-84$ \\
\hline TNF- $\alpha$ /pulse rate & 0.498 & -0.095 & 0.3943 \\
\hline TNF- $\alpha$ /respiration rate & 0.5255 & -0.3083 & -0.0565 \\
\hline TNF- $\alpha$ /body temperature & 0.7188 & 0.7494 & 0.4834 \\
\hline
\end{tabular}

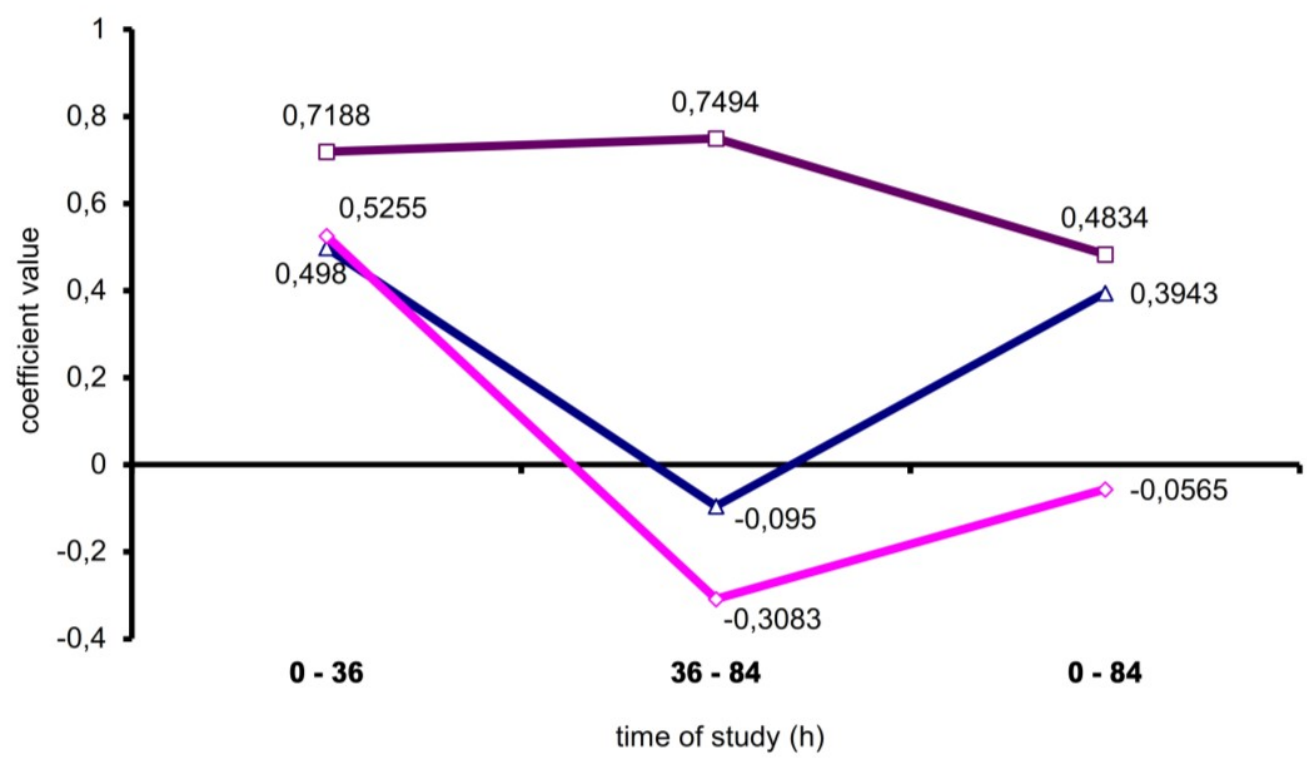

$\triangle$ TNF-a/pulse rate $\leadsto$ TNF-a/respiration rate $-\square$ TNF-a/body temperature

Fig. 4. Changes of correlation coefficient values during the study 


\section{Discussion}

The results published by other authors and our own observations indicate that TNF- $\alpha$ concentration increases significantly in the $84^{\text {th }} \mathrm{h}$ post burn $(10,14)$. Jeschke et al. (14) and Dehne et al. (9) claim that the concentration of IL- 6 and IL- 8 as well as TNF- $\alpha$ after burns in humans were dependent on the extent of those burns. Jeschke et al. (14) showed the correlation between the dynamics of TNF- $\alpha$ concentration increase and the extent of the burn, however, these results have not been confirmed by other authors (22). The majority of the authors agree that the TNF- $\alpha$ concentration increases after a burn injury, although some state that the concentration of TNF- $\alpha$ in human burn patients does not differ from the concentration in the control group, or is only marginally higher (approximately 1.52.5 times) in the post-burn period $(10,12)$. In burned patients, TNF- $\alpha$ serum concentration is low and increases 5-fold only during the first week after the burn (10). There have been many animal burn models developed, which allow the monitoring of the concentration of inflammatory mediators. Studies by Chen et al. (6) carried out on cavia domestica reveal that after suffering burns over $30 \%$ of the body surface, TNF- $\alpha$ increases rapidly between the $6^{\text {th }}$ and $16^{\text {th }} \mathrm{h}$ and then drops to the level observed in the $8^{\text {th }} \mathrm{h}$ of the study. Studies on rabbits by Liang et al. (17) proved a significant increase in serum TNF- $\alpha$ concentration after $1 \mathrm{~h}$ post burn. Other authors report a regular increase in TNF- $\alpha$ concentration in rabbits' serum, persisting up to the $16^{\text {th }} \mathrm{h}$ post burn (25). Liu (19), on the other hand, in his study on rats showed a $30 \%-50 \%$ increase of TNF- $\alpha$ concentration in serum from the $6^{\text {th }}$ to the $48^{\text {th }} \mathrm{h}$ post burn.

It seems that the type of burn may influence the changes in serum TNF- $\alpha$ concentration. Studies of inhalation burns performed on swine reveal a decrease in TNF- $\alpha$ concentration in serum until the $72^{\text {nd }} h$, compared to the control group (18).

In this study, it was proved that TNF- $\alpha$ concentration in serum increases up to the $36^{\text {th }} \mathrm{h}$ of the experiment, and the increase persists to the $84^{\text {th }} \mathrm{h}$ post burn. The increase in TNF- $\alpha$ concentration in serum from the 0 to $36^{\text {th }} \mathrm{h}$ of the study was correlated with the increase in body temperature in burnt animals (Fig. 4, Table 1). In this one-and-a-half day period, a positive correlation between the changes in TNF- $\alpha$ concentration and the respiration and pulse rates of the burn animals can be observed. Between the $36^{\text {th }}$ and $84^{\text {th }} \mathrm{h}$ after the burn, the correlation between TNF- $\alpha$ and respiration rate weakens. During the whole study, a steady increase in body temperature in burn animals and a positive correlation between TNF- $\alpha$ and body temperature were observed. This proves that TNF- $\alpha$ is an important inflammatory mediator, influencing body temperature after burns. During the research, the respiration rate in the burn group was significantly higher compared to the control group. The final wholetimeline correlation coefficient of TNF- $\alpha /$ respiration rate was negative, although initially, between the 0 and $36^{\text {th }} \mathrm{h}$, the coefficient $\mathrm{r}$ was clearly positive for this correlation (Fig. 4, Table 1). It is worth noting that both variables maintained an increase compared to the control group during the study.

The above observations indicate that an increase in respiration rate up to the $36^{\text {th }} \mathrm{h}$ of the experiment is caused mainly by an increase in TNF- $\alpha$ concentration in serum. Nevertheless, after the $36^{\text {th }} \mathrm{h}$ other inflammatory mediators are also responsible for shaping this parameter. This observation seems to correlate with the findings, revealing that after the $36^{\text {th }} \mathrm{h}$ following a burn a systemic inflammation in the form of SIRS develops, accompanied by acute inflammation phase response $(7,23)$, which can have a direct effect on respiratory response. A statistically significant increase in pulse rate occurs between the time of the burn injury and the $36^{\text {th }} \mathrm{h}$ post burn, followed by its decrease below the pulse rate values of the control group (Fig. 2). During the whole experiment $\left(0-84^{\text {th }} \mathrm{h}\right)$, a positive correlation between serum TNF- $\alpha$ concentration and pulse rate in the burn animals was determined (Fig. 4, Table 1). There are no reports on the above dependencies concerning severe skin burns in swine in the available literature. As results from research works, the demonstration of this assertion as true is crucial because of high correlation between the severity of the burn and the spontaneous burning response. The possibility of using the patented T/B procedure facilitated the research and gave the opportunity to get a burn of the desired severity, saving the parameters used and using identical parameters in each case. Among many inflammatory markers, TNF- $\alpha$ is a key cytokine, influencing metabolism after burns. It should be emphasised that the research project was strictly implemented in terms of surface area and the degree of thermal injury. Nevertheless, an increase in cytokine concentration after a burn injury is induced by a complex interaction of inflammation forming factors where many agents are in play. The data obtained during the study allows us to assume that there exist interrelationships between TNF- $\alpha$ serum concentration and pulse and respiration rates in the period of a rapid and significant rise in the level of this cytokine. However, an increase and persistence of elevated values of these clinical parameters is not mono causative and must not be assigned exclusively to the elevated level of this cytokine (21). The obtained results and observations may be a contribution to the design of further research into the syndrome of systemic inflammatory response, multi-organ failure syndrome, and sepsis, syndromes which are still a significant cause of death of both humans and animals. Research conducted in this field is important, and its results are valuable for new treatment strategies not only for the heavily burned, but also for the 
treatment of massive multi-organ injuries. Such a conclusion is drawn in the studies of many authors $(5$, $10,14,19,22,27)$.

Conflict of Interests Statements: The authors declare that there is no conflict of interests regarding the publication of this article.

Financial Disclosure Statement: The authors declare that this study was financed by statutory activity of the Society of Silesian Veterinary Polyclinics and the authors' own funds.

Animal Rights Statement: The authors declare that the experiments on animals were conducted in accordance with local Ethical Committee laws and regulations as regards care and use of laboratory animals. The consent for the research was granted by the $1^{\text {st }}$ Local Ethics Committee for Animal Experiments of Jagiellonian University in Kraków.

\section{References}

1. Aleksiewicz R., Budzińska Z., Fabisz A.: Clinical aspects of thermal burns in animals, etiology and therapy Med Weter 2009, 65, 526-532.

2. Aleksiewicz R., Lisiecka B., Niedziela D.: Leczenie oparzeń termicznych u zwierząt. Wet Prakt 2008, 6, 8-12.

3. Bone R.C.: Sepsis, the sepsis syndrome, multi-organ failure: a plea for comparable definitions. Ann Intern Med 1991, 114, 332-333.

4. Calixto J.B., Cabrini D.A., Ferreira J., Campos M.M.: Kinins in pain and inflammation. Pain 2000, 87, 1-5.

5. Chang D., Jia J, Zang B.: Changes in plasma interleukin-33 concentration in sepsis and its correlation with seriousness of sepsis. Zhonghua Wei Zhong Bing Ji Jiu Yi Xue 2015, 27, 138-142.

6. Chen J., Zhon Y., Rong X.: An experimental study on systemic inflammatory response syndrome induced by subeschar tissue fluid. Burns 2000, 26, 149-155.

7. Choileain N.N., Redmond H.P.: Cell Response to Surgery. Arch Surg 2006, 141, 1132-1140.

8. Dahiya P.: Burns as a model of SIRS. Front Biosci 2009, 14, 4962-4967.

9. Dehne M.G., Sablotzki A., Hoffmann A., Muhling J., Dietrich F.E.,: Hempelmann G.: Alteration of acute phase reaction and cytokine production in patients following severe burn injury. Burns 2002, 28, 535-542.

10. Finnerty C.C., Herndon D.N., Przkora R., Pereira C.T., Oliveira H.M., Queiroz D.M., Rocha A.M., Jeschke M.G.: Cytokine expression profile over time in severely burned pediatric patients. Shock 2006, 26, 13-19.

11. Finnerty C.C., Jeschke M.G., Herndon D.N., Gamelli R., Gibran N., Klein M., Silver G., Arnoldo B., Remick D., Tompkins R.G.: Temporal cytokine profiles in severely burned patients: a comparison of adults and children. Mol Med 2008, 14, 553-560.

12. Guanying L., Lan Y., Wei T., Xuguo Z. Yaonan L., Duyin J.: A novel dermal matrix generated from burned skin as a promising substitute for deep-degree burns therapy Mol Med Rep 2016, 13, 2570-2582.

13. Jeschke M.G., Gauglitz G.G., Kulp G.A., Finnerty C.C., Williams F.N., Kraft R., Suman O.E., Mlcak R.P., Herdon D.N.: Long-term persistance of the pathophysiologic response to severe burn injury. PLoS ONE 2011, 6, 212245. doi.org/ 10.1371/journal.pone.0021245.

14. Jeschke M.G., Mlcak R.P., Finnerty C.C., Norbury W.B., Gauglitz G.G., Kulp G.A., Herdon D.N.: Burn size determines the inflammatory and hypermetabolic response. Crit Care 2007. 11, R90.

15. Jobe K.L., Odman-Ghazi S.O., Whalen M.M., Vercruysse K.P.: Interleukin-12 release from macrophages by hyaluronan, chondroitin sulfate $\mathrm{A}$ and chondroitin sulfate $\mathrm{C}$ oligosaccharides. Immunol Lett 2003, 89, 99-109.

16. LaRosa S.P., Opal S.M.: Sepsis strategies in development. Clin Chest Med 2008, 29, 735-747.

17. Liang R., Rong X., Zhang T., Shen Y., Dai L., Huang Y.: Effect of mannitol on serum tumor necrosis factor- $\alpha$ and interleukin- 6 levels and the mechanism of its organ-protective effect in rabbits early after severe burn injury. Nan Fang Yi Ke Da Xue Xue Bao 2013, 33, 598-602.

18. Linden K., Scaravilli V., Kreyer S.F., Belenkiy S.M., Stewart I.J., Chung K.K., Cancio L.C., Batchinsky A.I.: Evaluation of the Cytosorb ${ }^{\mathrm{TM}}$ Hemoadsorptive Column in a pig model of severe smoke and burn injury. Shock 2015, 44, 487-495.

19. Liu L., Li X., Yang J., Chai J., Yu Y., Duan H., Song H., Feng R., Wang T., Yin H., Hu Q., Wang S., Du J.: Comparison of systemic inflammation response and vital organ damage induced by severe burns in different area. Int J Clin Exp Pathol 2015, 1, 6367-6376.

20. Lowry S.F.: The evolution of an inflammatory response. Surg Infect 2009, 10, 419-425.

21. Ozbalkan Z., Aslar A.K., Yildiz Y., Aksaray S.: Investigation of the course of proinflammatory and anti-inflammatory cytokines after burn sepsis. Int J Clin Pract 2004, 58, 125-129.

22. Palmer J.L., Deburghgraeve C.R., Bird M.D., Hauer-Jensen M., Kovacs E.J.: Development of a combined radiation and burn injury model. J Burn Care Res 2011, 32, 317-323.

23. Sobieska M., Mikstacki A., Wiktorowicz K.: Changes in concentrations of cytokines and chosen acute phase proteins after polytrauma. Nowiny Lek 1998, 67, 515-523.

24. Swindle M.M., Makin A., Herron A.J., Clubb F.J., Frazier K.S.: Swine as models in biomedical research and toxicology testing. Vet Pathol 2012, 49, 344-356.

25. Tan X.D., Dai F., Wang J.H.: Effects of early administration of imipenem on subeshcar and plasma TNF- $\alpha$ in rabbits with severe burns. Di Yi Jun Yi Da Xue Xue Bao 2004, 24, 1444-1446.

26. Vaday G.G., Lider O.: Extracellular matrix moieties, cytokines, and enzymes; dynamic effect on immune cell behavior and inflammation. J Leukoc Biol 2000, 67, 149-159.

27. Williams F.N., Herndon D.N., Jeschke M.G.: The hypermetabolic response to burn injury and interventions to modify this response. Clin Plast Surg 2009, 36, 583-596. 